\title{
LA CIUDAD DE LA PLATA: DOS TIPOS Y UN ARQUETIPO DE LA PLANIFICACIÓN URBANA EN ARGENTINA
}

Manuel Fernando Mujica*

Imagen A: La imagen representa el núcleo original de la ciudad de La Plata, proyectado por el Ingeniero Pedro Benoit. Imagen disponible en Internet en: http://www.bibliocad.com/

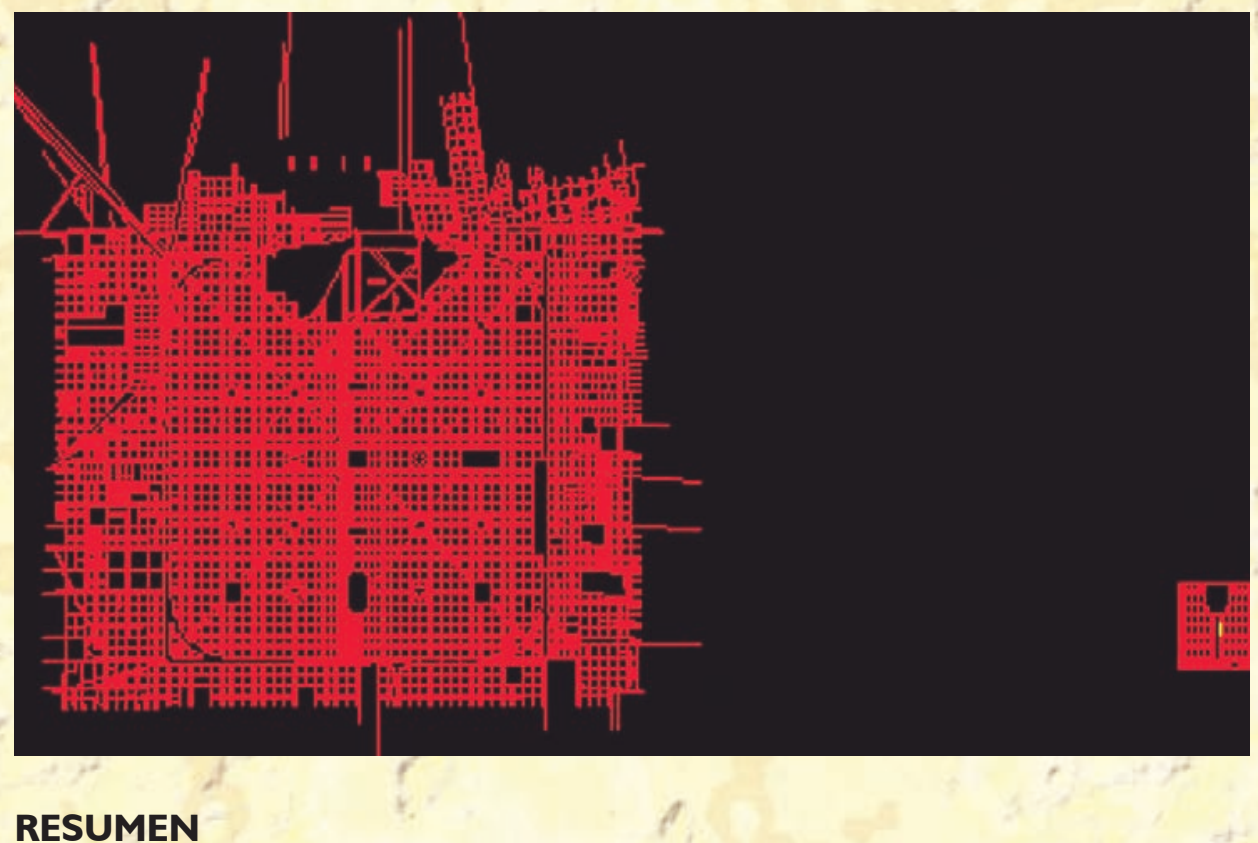

Se entienden como Nuevas Ciudades, los núcleos urbanos que no han nacido espontáneamente sino sobre la base de un proyecto urbano específico que empieza a desarrollarse a partir de su núcleo de fundación, por lo general en tiempos breves, con rapidez y con una forma geométrica precisa. Sin embargo, no siempre, la distinción entre la formación urbana espontánea y planificada es totalmente claro como tampoco son determinativos el tiempo breve de la construcción y la regularidad de la conformación geométrica ya que hay centros urbanos planificados con geometría irregular o no necesariamente simétrica. ' Se podría decir que estos proyectos se caracterizan por provenir de una reflexión sobre la ciudad ideal, seguramente asumido por sus planificadores en un momento dado antes de la elaboración del proyecto. Es así que las ciudades nuevas a menudo adoptan un trazado regular (damero, estrella, entre otros) y sus edificios públicos, así como la organización de los servicios, responden a un programa específico con determinantes sociales o intelectuales. En otra palabras, un deseo de orden que se inscribe dentro de un tejido urbano que encarna diferentes visiones y dimensiones para responder a diferentes retos que han sido abordados por la historia de la arquitectura en muchísimas ocasiones: desde las ideas de Platón y Aristóteles, y la descripción de cómo debe ser la ciudad de Vitrubio, los pensamientos del Siglo XVIII, hasta llegar a las propuestas del movimiento moderno tales como la utópica Usonia de Wright o la ciudad radiante de Le Corbusier. ${ }^{2}$ En América Latina el boom de las ciudades planificadas no es nuevo ya que vio un inicio con matices europeos después de la llegada de los españoles y la implantación de las Leyes de Indias. Siglos más tarde, una "nueva temporada de ciudades nuevas" llega a América con las secuelas de la Revolución Industrial, materializándose en algunos proyectos que han sido objeto de investigación en la Cátedra de Teorías Urbano Ambientales, como es el caso de La Ciudad de La Plata en Argentina, de la cual este artículo presenta sucintamente sus origines y planificadores.

\section{PALABRAS CLAVE}

Ciudad de La Plata, diagonales, diseño, orden, proyecto, trazado.

Piccinato, L., Urbanística medieval, Ed.Dedalo, Bari, 1978

2 Benedetto Gravagnuolo. Historia del urbanismo en Europa, 1750-1960. Madrid, Ediciones Akal, 1998 


\section{THE CITY OF LA PLATA: TWO TYPES AND ONE ARCHETYPE OF URBAN PLANNING IN ARGENTINA}

Manuel Fernando Mujica*

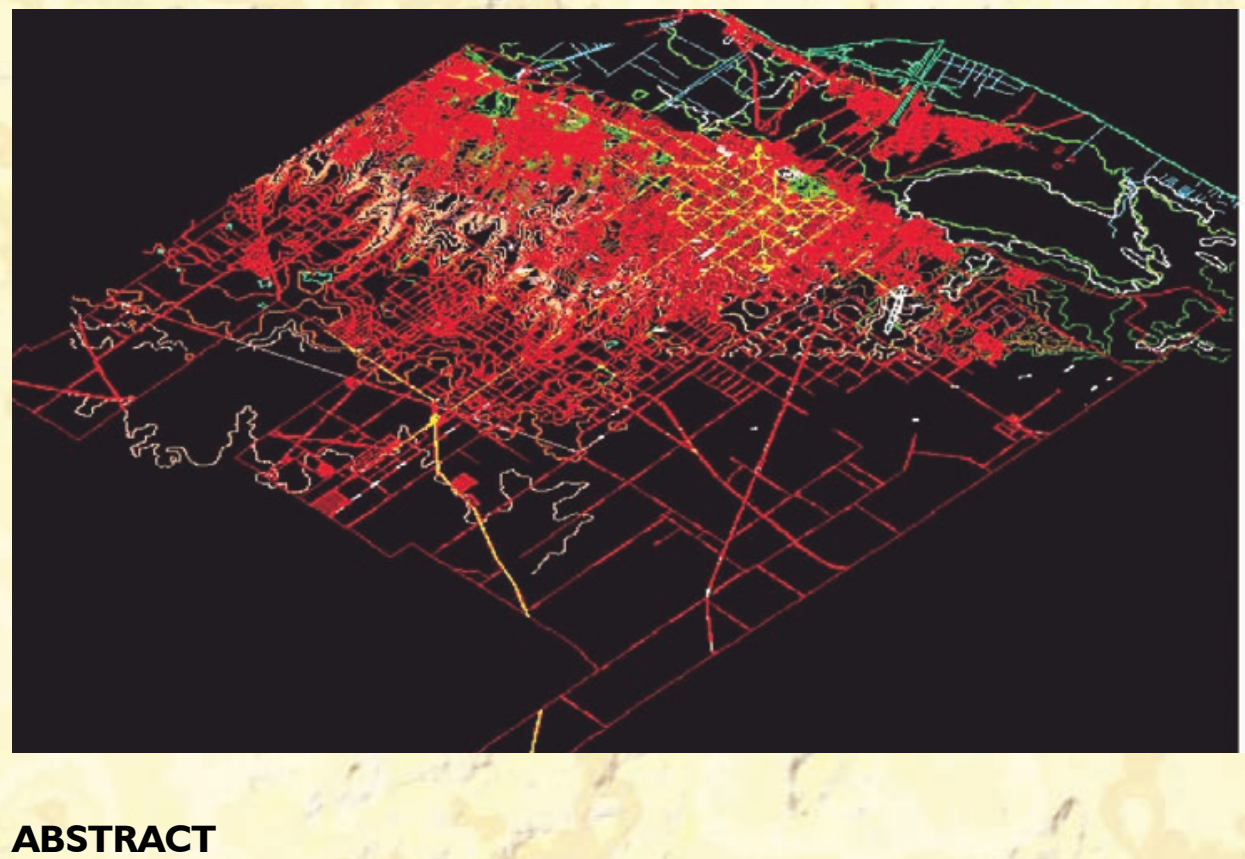

New Cities are understood as towns that were not born spontaneously but on the basis of a specific urban project that begins to develop from its core foundation, usually within a short time, quickly and with an accurate geometric shape. However, the distinction between a spontaneous and planned urban settlement is not always entirely clear, neither are the short time periods of construction and the regularity of the geometric shape determinative, as there are planned urban centers with irregular geometry and designs that are not necessarily symmetric. It could be said that these projects are come from a reflection on the ideal city, probably made by the planners at some point before the development of the project. Thus, the new towns often take a regular pattern (checkerboard pattern, star, among others) and their public buildings and the organization of services denote a specific plan with social or intellectual determinants. In other words, a desire for order within a planned urban grid that embodies different points of views and dimensions in order to respond to different challenges that have been approached by the history of architecture in many occasions: from the ideas of Plato and Aristotle and the Vitruvius description of how the city should be, the thoughts of the Eighteenth Century until the proposals of the modern movement such as the utopia Usonia of Wright or Le Corbusier's Radiant City. In Latin America the boom of planned cities is not new, and after the arrival of the Spaniards and the implementation of the Laws of the Indies planned cities saw a beginning with European nuances. Centuries later, a new season of planned cities in America came in the aftermath of the Industrial Revolution, embodied in some projects that have been investigated in the course of Urban and Environmental Theories; among them this article outlines the case of The City of La Plata in Argentina, its origins and its planners.

\section{KEY WORDS}

City of La Plata, diagonal design, order, design, layout. jo de investigación en aula de la cátedra de Teorías Urbano Ambientales.

* Docente: Arq. PhD Carlos Humberto Gómez Arciniegas
Imagen B: La Plata y su crecimiento urbano hasta el 2010. Imagen disponible en Internet en: http://www.bibliocad.com/ 


\section{INTRODUCCIÓN}

Las últimas décadas del siglo XVIII estuvieron acompañadas por un notable desarrollo en las artes y las ciencias en Europa, propiciados por la llustración, un movimiento cultural que nace en Inglaterra y repercute fuertemente en Francia y se caracteriza por la reafirmación del poder de la razón humana frente a dogmas de la fe y la superstición. ${ }^{3}$ Por otra parte, el sistema social también sufre cambios radicales debido al colapso del feudalismo, el cuestionamiento del vasallaje y en gran parte por el advenimiento en Inglaterra de la Revolución industrial y el crecimiento económico de Europa ${ }^{4}$ Llega entonces el siglo XIX, lleno de fuertes cambios en todos los ámbitos de la vida y el conocimiento, anunciados $y$ gestados en el pasado pero que se efectuarían, de hecho, a lo largo de sus cien años. Esto para decir que en el siglo XIX se reconocen los principales rasgos de la diferenciación social del espacio y las condiciones de vida, circunstancias que comenzarían a cincelar las grandes ciudades y a influir en ciertas mentes que optarían por pensar en la ciudad ideal como solución a muchos problemas que se incrustaron en los cascos urbanos por la industrialización. Sin embargo, muchos países europeos afrontaban situaciones de crisis y despotismos humanos que más adelante se reverterían en situaciones extremas como las guerras Mundiales.

El panorama no era muy diferente en América del Sur en términos de paz, pues en muchos países se desataron conflictos internos que se alternaban con luchas por la delimitación de sus fronteras o por simples cuestiones de supremacía doméstica. La Ciudad de La Plata es un ejemplo verídico, surgido a raíz de una guerra civil argentina que luchaba por la autonomía de Buenos Aires como capital Federal y dejaba a la Provincia de Buenos Aires sin una capital (Ver Imagen I). Así es que el entonces gobernador bonaerense apuesta, junto al urbanista Pedro Benoit por proyectar una ciudad nueva, no muy distante de la metrópoli y que serviría como paradigma de planificación para ciudades que más tarde se asentarían en países como Brasil, el cual se lanzó en esta empresa de las Nuevas Ciudades con Belo Horizonte, predecesora de Brasilia, entre otras ${ }^{5}$. En realidad, Pedro Benoit tenía una doble raíz que lo catapultó a ese rol histórico. Era descendiente de franceses, y tenía dichas ideas humanistas ilustradas bien arraigadas en el iluminismo positivista que el país de su padre lideró 6 . El presente artículo resume por lo tanto, los aspectos más importantes sobre los orígenes de La Plata, sus dos protagonistas principales, su construcción, su localización, la arquitectura de la ciudad y naturalmente los criterios más sobresalientes de su planificación urbanística entre otros que ponen a este centro urbano como un arquetipo del diseño urbano en Argentina y probablemente en Suramérica.

\section{LA CIUDAD DE LA PLATA Y SUS ARTÍFICES}

La ciudad de la Plata nace más por determinantes políticas que por exigencias demográficas o por cuestiones de índole geográfica o productiva. Es así que este centro urbano se funda el 19 de noviembre 1882 por el entonces Gobernador Provincial Juan José Dardo Rocha y Arana (1838-192I) como consecuencia de la falta de una capital para la provincia de Buenos Aires, después de la declaración de 1880 que convertía a Buenos Aires en Capital Federal de Argentina (Ver Imagen 2). En otras palabras, una maniobra de Dardo Rocha para dar la solución a un conflicto político doméstico que lo obligaba a instalar su gobierno y administración en otra ciudad, dar a la Provincia de Buenos Aires una nueva capital y

La llustración. ttp://www.rinconcastellano.com/ilustracion/ilustracion.html

Morris A.J., Historia de la forma urbana : desde sus orígenes hasta la Revolución industrial, Barcelona, Gustavo Gili, 1984 Bello Horizonte se construye desde I894 a I 897 ganándose el puesto como la primera ciudad brasileña moderna planificada. El ingeniero Aarão Reis fue quien la proyectó. MUNIZAGA VIGIL, Gustavo. Diseño Urbano: Teoría y Método. Santiago, Editorial Alfaomega, 2002

6 Pedro Benoit. Hacedor de un Plan Prodigioso. http://www.eldia.com.ar/especiales/proceres/n9.htm 

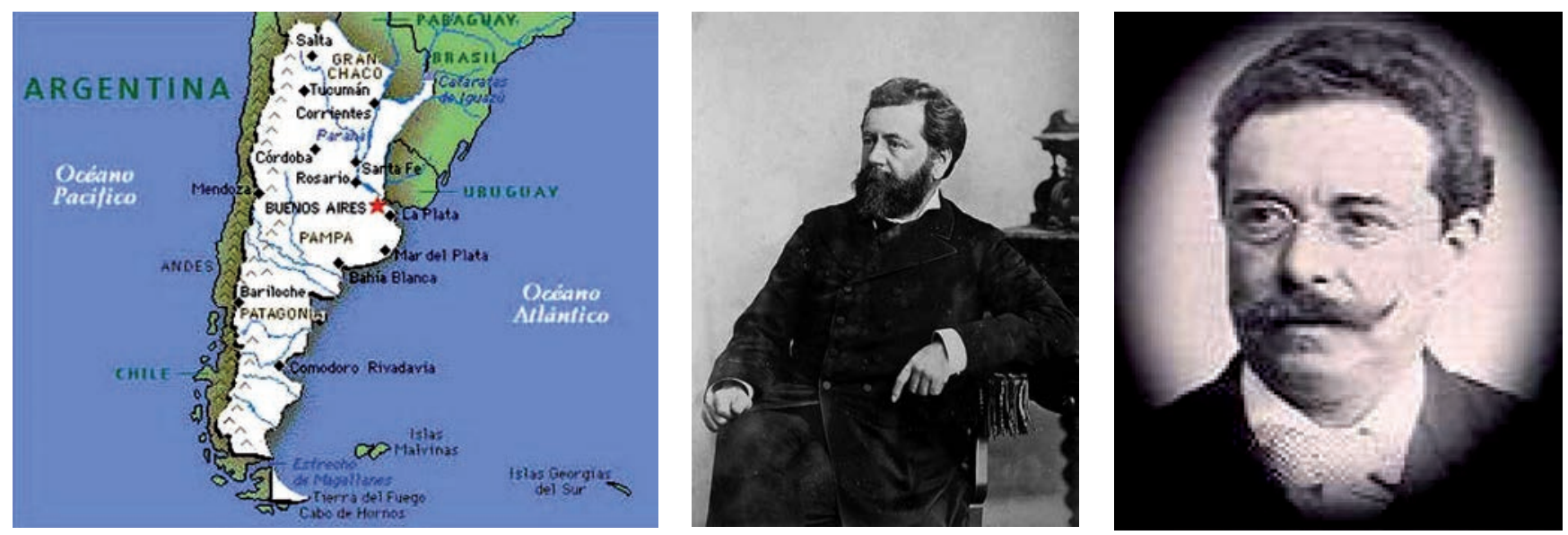

A la izquierda. Imagen I. Localización geográfica de La Plata y la Provincia de Buenos Aires en el territorio argentino. www. http://www.welcomeargentina.com/

En el centro: $\quad$ Imagen 2. Juan José Dardo Rocha y Arana. Juan José Dardo Rocha y Arana, además de militar, era abogado, político y diplomático, se destaca en la historia argentina por su tarea como Gobernador de la Provincia de Buenos Aires, ya que a él se debe la existencia de su capital, la Ciudad de la Plata (nombre elegido por José Hernández y diseñada por Pedro Benoit). Imagen disponible en Internet en: http://www.logiaconstancia.org

A la derecha: $\quad$ Imagen 3. Pedro Benoit. El trazado de la ciudad lo realizó Pedro Benoit, jefe del Departamento de Ingenieros de la Provincia de Buenos Aires. Si bien no se conserva el plano original, el planteamiento urbano es de su autoría. Pedro Benoit fue hombre de confianza del Dr. Dardo Rocha y uno de los motores de la importante obra, considerada original e innovadora pues Rocha y Benoit no copiaron exactamente ninguna ciudad existente. La Plata. Traza de la Ciudad. Disponible en Internet en: http:// www.interlap.com.ar

dejar a la entonces económicamente poderosa ciudad de Buenos Aires una condición mas emancipada, hoy reflejada en su estatus de Ciudad Autónoma, llamada también Capital Federal por ser sede del gobierno federal. ${ }^{7}$

Es así que el proyecto de construcción de La Plata ve un inicio cuando Dardo Rocha envía el proyecto de Ley que otorga a la ciudad su condición de nueva capital de la provincia que nomina para el diseño del nuevo centro urbano al arquitecto, urbanista e ingeniero Pedro Benoit (I836-1897) quien trazó los planos de la futura capital de la provincia (Ver imagen 3). Finalmente, el 19 de noviembre de 1882 se colocó la piedra fundamental en el centro de la futura ciudad después de un discurso de Dardo Rocha en el cual pronunció las siguientes palabras:

«Hemos dado a la nueva capital el nombre del río magnífico que la baña, y depositamos bajo esta piedra, esperando que aquí queden sepultadas para siempre, las rivalidades, los odios, los rencores, y todas las pasiones que han retardado por tanto tiempo la prosperidad de nuestro país»".

Desde este momento inicia el desarrollo de la ciudad en múltiples aspectos que la llevarán a albergar en su tejido urbano varias construcciones que aun testimonian su carácter de ciudad planificada y promotora de paz y desarrollo. De hecho, su fundador se convierte en 1897 en el primer rector de la Universidad de La Plata, cargo que desempeñó hasta su nacionalización en 1905. En la misma fue titular de la cátedra de Derecho Constitucional. Dardo Rocha, antes de fallecer en la Ciudad de Buenos Aires el 6 de septiembre de 1921, también tuvo un desempeño decisivo en las negociaciones sobre límites con Chile y Bolivia?.

$7 \quad$ LEVENE, Ricardo. Historia Argentina y Americana. Ministerio de Cultura de Buenos Aires, Buenos Aires, 2010

8 BARBA, Fernando Enrique. Historia de la municipalidad de La Plata. Acción de los gobiernos municipales entre 1882 y 1998. Banco Municipal de la Plata, La Plata, 1999 [I Ed.]

9 Ibídem 


\section{EL PROYECTO URBANO}

Como se mencionó en líneas anteriores, el principal protagonista de la planificación urbana de la Plata fue Pedro Benoit, arquitecto, ingeniero y urbanista, conocido en el ámbito político por su labor destacada en la construcción de fortificaciones y el emplazamiento de baterías para la defensa de la Capital argentina, tiempo en el cual, desde su función en el Departamento de Ingenieros de la Provincia de Buenos Aires, inicia los trabajos de ubicación y construcción de la nueva capital de la Provincia de Buenos Aires: La Plata. La ubicación del proyecto fue fruto de un proceso de concertación y búsqueda por un entorno ideal, liderado por Dardo y Rocha y sus colaboradores, decidiéndose erigir la ciudad 10 kilómetros tierra adentro en las Lomas de Ensenada, terrenos caracterizados por sus montes y varias corrientes de agua que desaguaban en el cercano Río de la Plata, en un entorno que le permite contar con un clima templado, reflejado en su temperatura media anual que ronda los 16,3 grados centígrados. Hoy la ciudad limita además con las localidades (o centros comunales) de Villa Elvira, Altos de San Lorenzo, Los Hornos, San Carlos y el partido (municipio) de Berisso, es la cabecera del partido homónimo (Ver Imagen 4. $)^{10}$

Imagen 4. Localidades vecinas a La Plata. Fuente: Google Earth

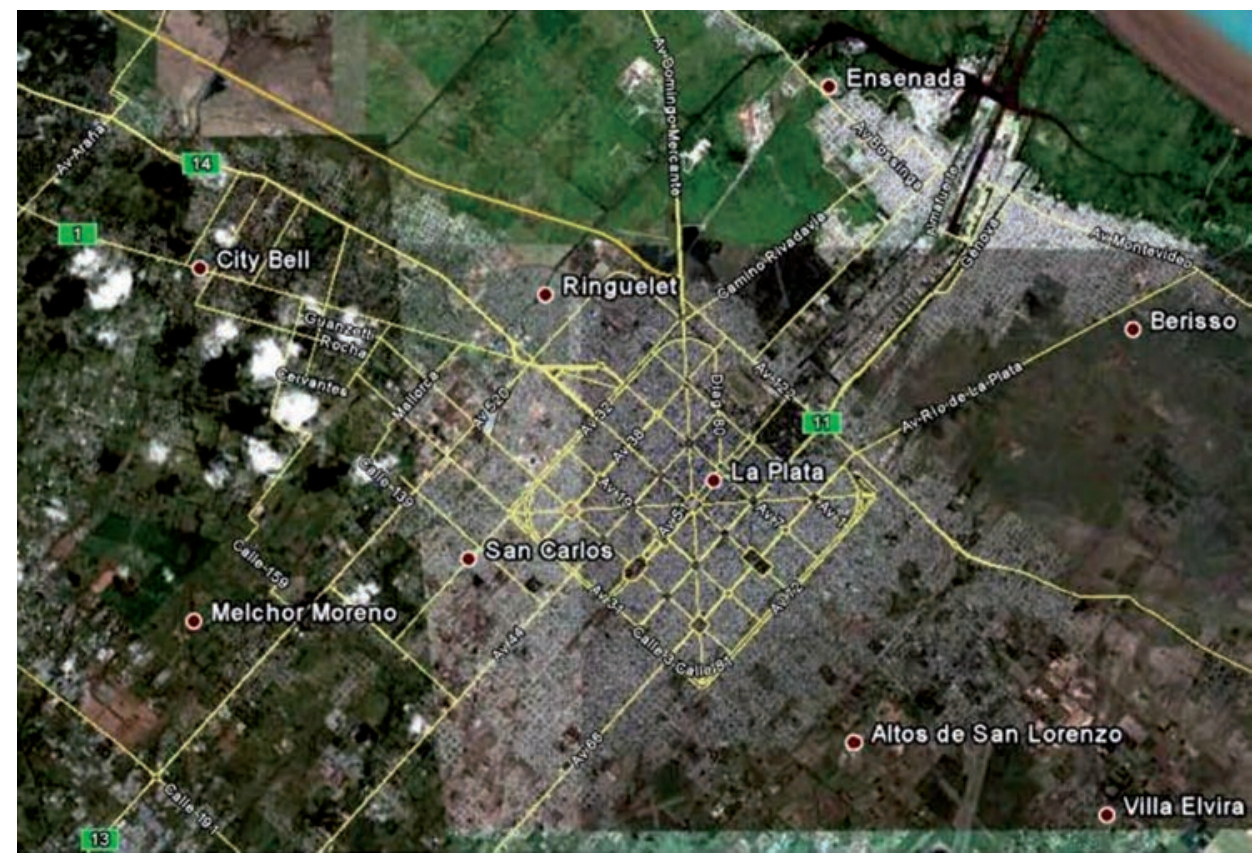

Una vez decidido el lugar, Pedro Benoit diseña un proyecto urbano caracterizado por numerosas diagonales que se interceptan sobre el trazado ortogonal de las vías que se cruzan en ángulo recto, de las cuales las más importantes convergen en Plaza Moreno, que fue prevista como lo que sería el centro geográfico de la ciudad, hoy convertida en una de la Plazas-Parque más grandes del mundo, custodiada después por las fachadas del Palacio Municipal y la imponente catedral en estilo neogótico, rojiza al ser de ladrillo, convertida en uno de los símbolos platenses (Ver Imagen 5. )"

Sin duda un interesante proyecto urbano, resultado del trabajo del equipo de urbanistas comandado por Pedro Benoit. Estudiosos y biógrafos de la ciudad consideran que sus creadores se inspiraron en teorías de Leonardo Da Vinci, lo cierto es que el proyecto

10 Ciudad de La Plata. Capital de la Provincia de Buenos Aires. http://www.interlap.com.ar

I I MUNIZAGA VIGIL, Gustavo. Las Ciudades y su Historia. Una aproximación. Santiago, Editorial Alfaomega, 2002 


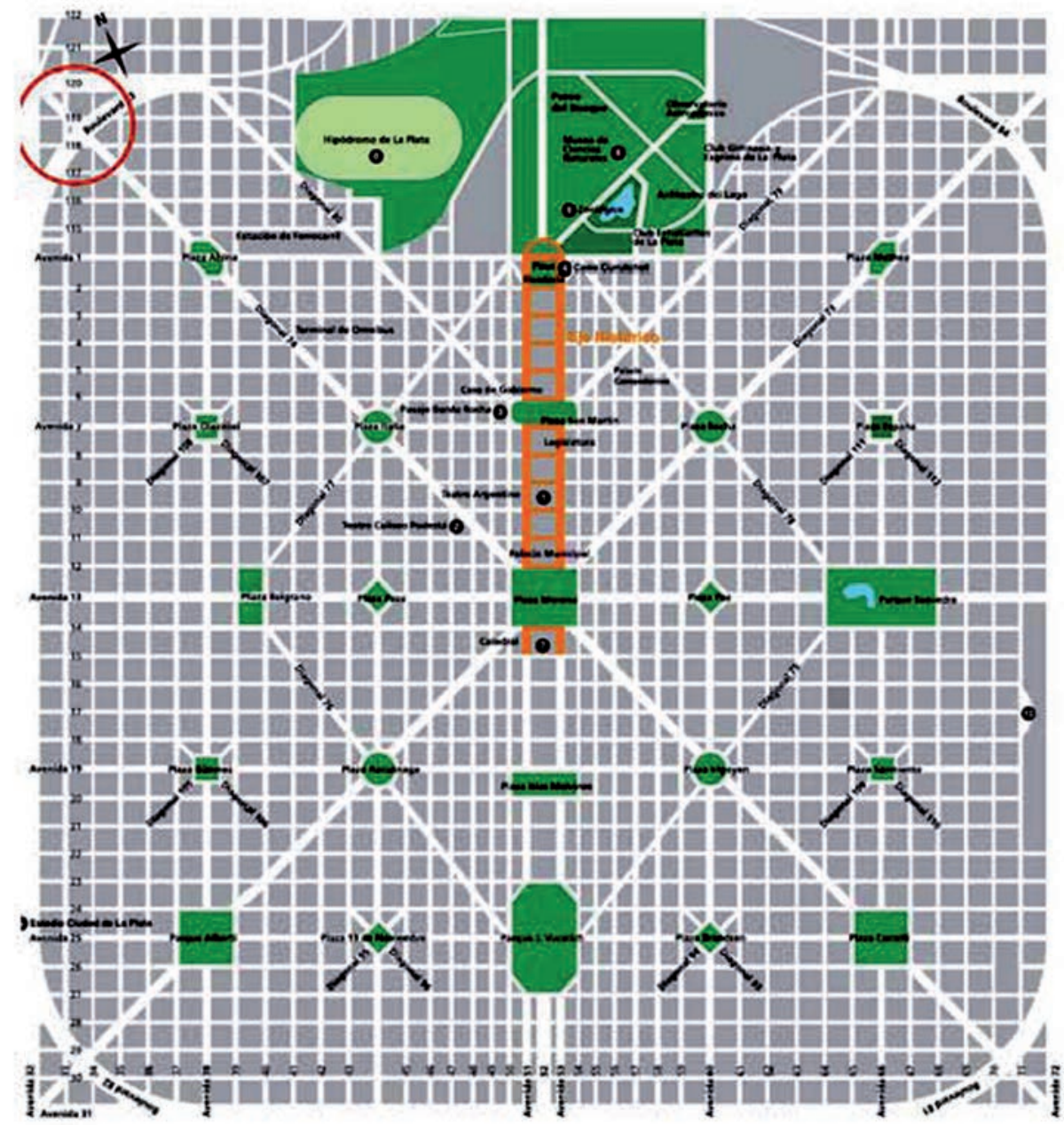

es original para la época y no copia al de ninguna ciudad conocida hasta el momento. De cualquier manera es claro que los planificadores de La Plata tomaron en cuenta "las primeras ideas de la ciencia urbanística fundada por Ildefonso Cerdá, el autor del Ensanche de la ciudad de Barcelona, y también las retículas norteamericanas, que por entonces se hacían presentes en la fundación de nuevas ciudades, sin dejar a un lado algunas buenas lecciones de la ciudad colonial en cuadrícula"'2. De hecho el trazado urbano de La Plata denota la adopción de patrones clásicos caracterizados por una "equilibrada y rigurosa composición" y que ahora permite que la ciudad sea reconocida a priori por la definición de sus límites en la forma de un cuadrado a través de una circunvalación perimetral. ${ }^{13}$ Destacan además las diagonales que cruzan la ciudad y a su vez forman unos rombos que se leen claramente sobre la trama de calles ortogonal, su parque Paseo del Bosque y sus plazas secundarias, implantadas con exactitud en el damero cada seis cuadras. Merecen también ser mencionadas las plazas que aparecen en los cruces entre avenidas y un eje cívico, que es a la vez eje de simetría de la composición, sobre el que se implantan los edificios públicos principales. Dos ejes secundarios, transversales al anterior, donde se ubican edificios ministeriales y otros edificios públicos importantes. Vale la pena anotar que las manzanas son regulares: un módulo cuadrado de $120 \times 120 \mathrm{~m} .{ }^{14}$

12 PESCl, Rubén. Próceres Platenses, Pedro Benoit. Hacedor de un Plan Prodigioso. Disponible en Internet en: http://www. eldia.com.ar

13 MUNIZAGA G., Op. Cit.

14 MUNIZAGA VIGIL, Gustavo. Diseño Urbano: Teoría y Método. Santiafo, Editorial Alfaomega, 2002

Imagen 5. Planimetría básica de la ciudad de La Plata. Resalta en el centro, la Plaza Moreno, situada sobre un eje cívico, que es a la vez eje de simetría de la composición, sobre el que se implantan los edificios públicos principales. Imagen disponible en Internet en: http:// mappery.com 
Imagen 6. Casco urbano de la ciudad de Lo Plata. En el plano se identifican las principales diagonales y avenidas de La Plata así como sus plazas y sus principales monumentos y edificios públicos. Imagen disponible en Internet en: http://mapas.owje.com
La cartografia estudiada refleja además cómo a partir de las avenidas 44 y 60, las manzanas reducen progresivamente su ancho "a medida que se aproximan al eje cívico, hasta los 60 metros, a efectos de absorber el mayor caudal circulatorio que se produciría en sentido axial". ${ }^{15}$ Resalta además en la malla urbana un gran pulmón verde que se conformó con el bosque de eucaliptos existentes que pertenecía a la estancia de Martín Iraola (Ver Imagen 6. $)^{16}$. La ciudad además está poblada de especies arbóreas que la caracterizan, especialmente por el tilos, árbol representativo de la ciudad aunque acusado de provocar alergias al ser una especie introducida ${ }^{17}$. Esto no impide que La Plata sea una ciudad muy verde, con amplios espacios abiertos como su parque mayor, popularmente conocido como El Bosque, pulmón de la ciudad que además es ejemplo de paisajismo por el modo como se alternan las especies nativas que se reflejan en su pintoresco lago.

Haciendo referencia a los principales edificios públicos que se insertan en el trazado urbano, cabe destacar que para seleccionar los mejores proyectos se llamó a concurso internacional. Estos edificios están localizados en el eje histórico o eje central de la ciudad, Avenida 5 I 53, conservados en forma intacta hasta hoy al igual que el diseño de su estructura urbana. Algunos de ellos se localizan en puntos periféricos de la ciudad y construidos en época de la fundación de la ciudad, como respuestas a exigencias de carácter internacional, plasmadas paulatinamente por la influencia de una fuerte presencia extranjera que se registra desde fines de 1882, con sus primeros habitantes, legiones de albañiles italianos que comenzaron a ocuparse de dichas obras fundacionales. ${ }^{18}$

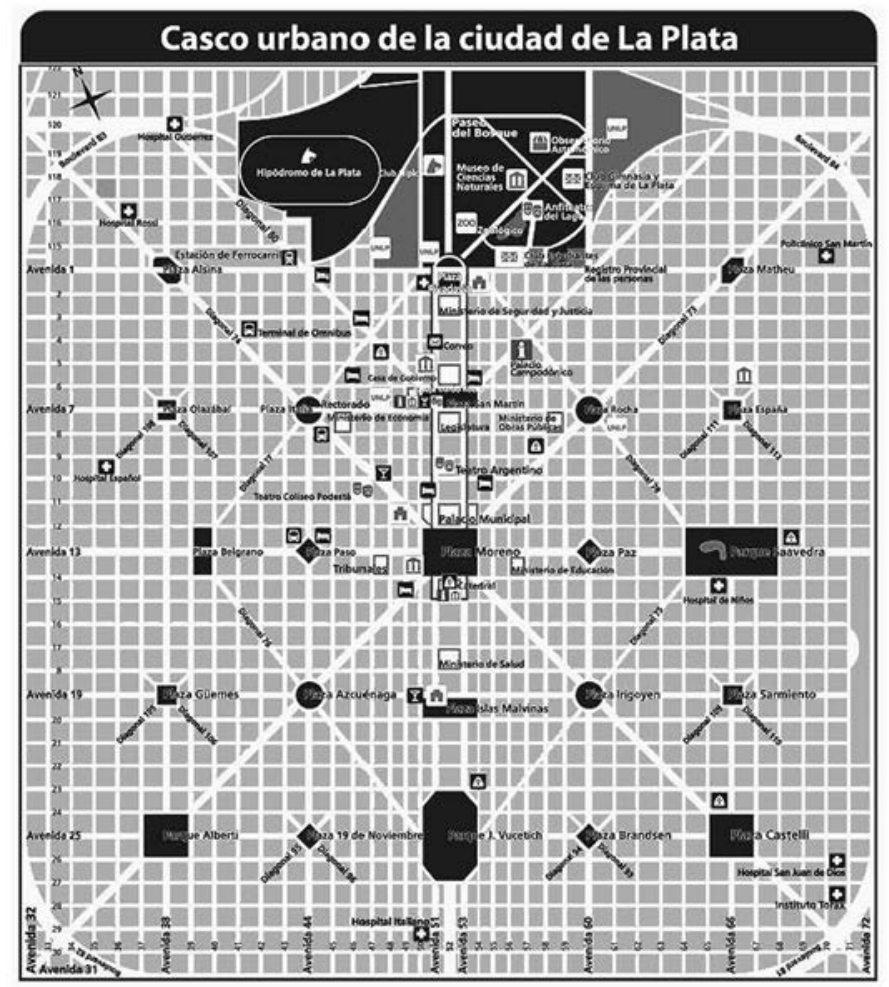

15 La Plata es la capital de la Provincia de Buenos Aires, http://www.arquba.com/monografias-de-arquitectura/ciudad-de-laplata/

16 Ciudad de La Plata. Capital de la Provincia de Buenos Aires. La Traza. Disponible en Internet en: http://www.interlap.com.ar

17 La ciudad de las diagonales, los tilos y los estornudos. Publicado en el Diario Hoy. La Plata, 2 de noviembre de 1998

18 La Ciudad de la Plata. Origen de la Ciudad. http://www.laplatainteractiva.com.ar 
De hecho, el primer censo de 1874 indicó que en la ciudad habitaban 10.407 personas (8.779 homarones y 1.628 mujeres) de la cuales sólo 1.278 eran argentinos y el resto extranjeros, llegados de e Italia, España, Francia, Portugal, Austria e Inglaterra. Regresando a los proyectos localizados en el eje histórico resaltan el Palacio Municipal de La Plata, cuya construcción se inició en 1883 . Un año más tarde, los poderes públicos de la Provincia son instalados definitivamente. ${ }^{19}$ Aparecen después edificios tales como el Museo de Ciencias Naturales (Imagen 7), la Casa de Gobierno (Imagen 8), el Centro Cultural Pasaje Dardo Rocha (Imagen 9), el Palacio Municipal (Imagen I0), el renovado Teatro Argentino (Imagen II), la Catedral (Imagen 12), el moderno estadio y el hipódromo. Merece también una mención la Universidad Nacional de La Plata UNLP que atrae estudiantes de toda la nación y da a la ciudad una atmosfera cultural y juvenil. ${ }^{20}$
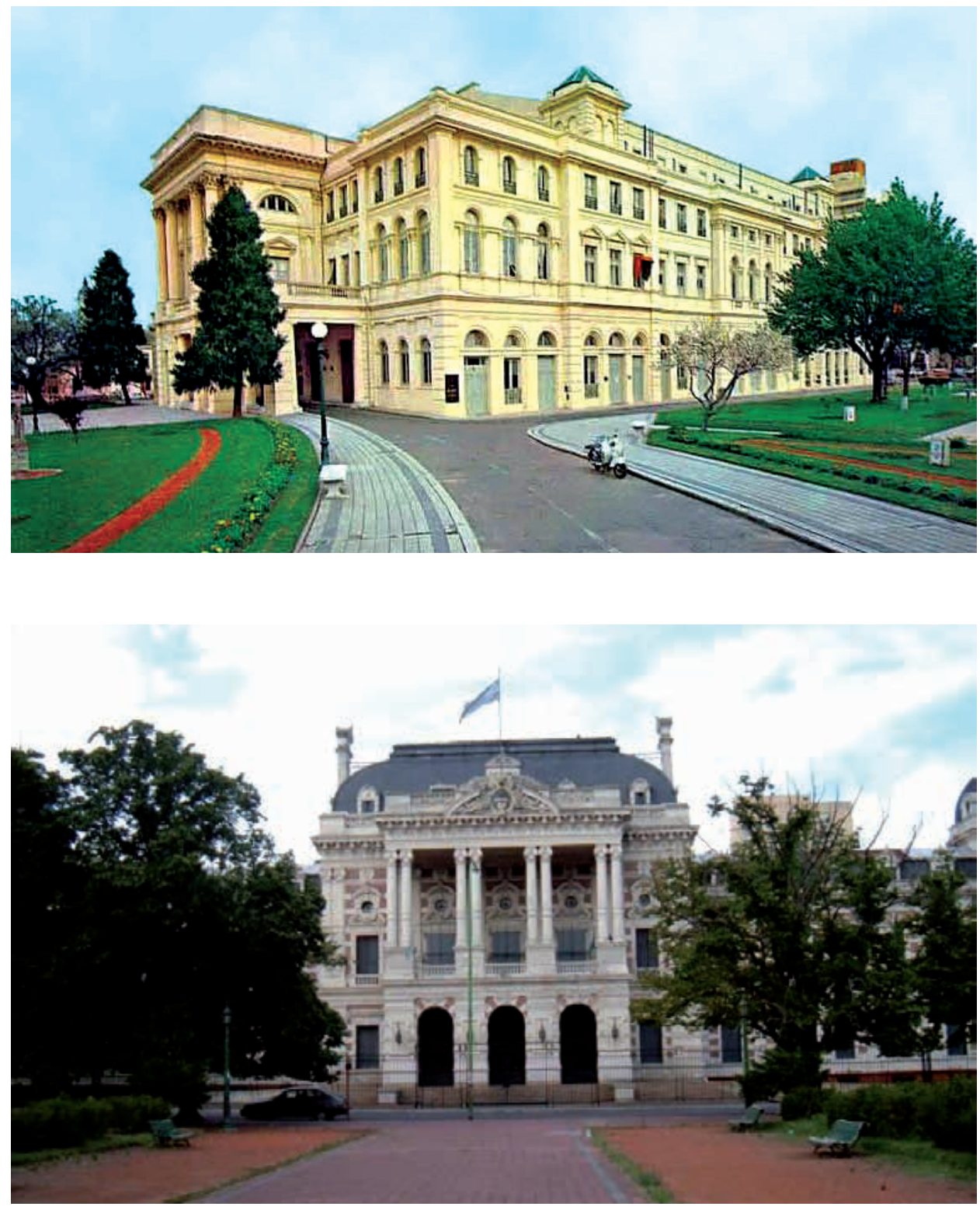

9 Ibidem

20 Universidad de La Plata, http://www.unlp.edu.ar/
Imagen 7. Museo de las Ciencias Naturales. El Museo de Ciencias Naturales antes del incendio que lo destruyó por completo. Imagen disponible en Internet en: http://www. skyscrapercity.com
Imagen 8. Casa de Gobierno. La Casa de Gobierno de la Provincia de Buenos Aires, se encuentra en el centro de la ciudad, en la manzana delimitada por las calles 51 y 53 , frente a la plaza San Martín. Imagen disponible en Internet en: http://www.skyscrapercity.com 
Imagen 9. Centro Cultural Pasaje Dardo Rocha. El Centro Cultural Pasaje Dardo Rocha, es uno de los edificios fundacionales más interesantes de la ciudad. Fue realizado por el ingeniero Pinaroli a la usanza de las grandes estaciones europeas y alojo la gran estacion de trenes. Ubicado en el corazón de la ciudad, fue en sus orígenes la Estación "19 de Noviembre", primera Terminal del Ferrocarril Oeste de La Plata. Hoy es escenario de los acontecimientos culturales más importantes de la ciudad. Disponible en Internet en: $h t t p: / / w w w . t r e k e a r t h . c o m /$
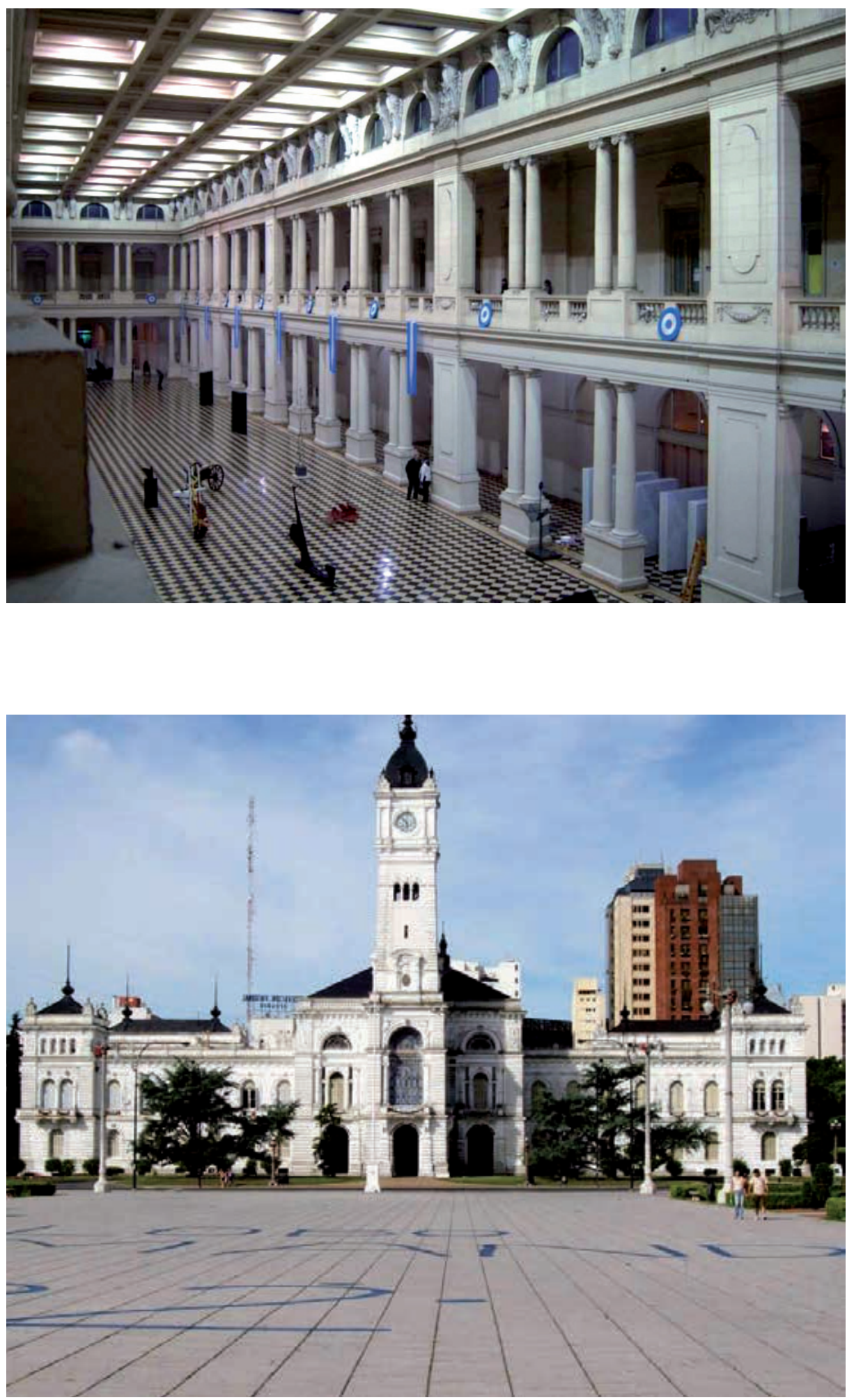

Imagen 10. Palacio Municipal. Uno de los edificios más reconociods de La Plata es el perteneciente a la Municipalidad. Separado de la Catedral por la plaza Moreno, ocupa la manzana delimitada por las avenidas 5 I y 53 y las calles II y I2. Imagen disponible en Internet en: http:// www.skyscrapercity.com 


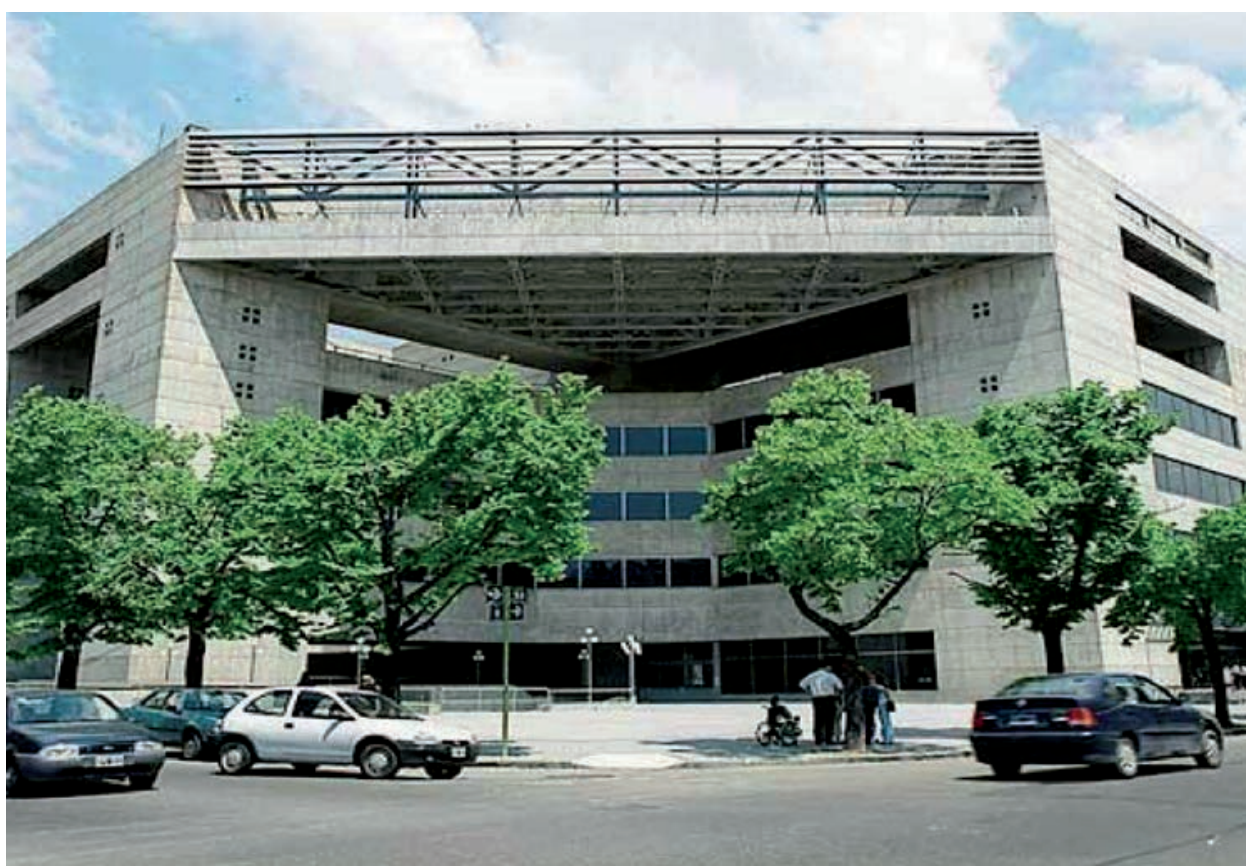

Imagen II. Teatro Argentino. El renovado Teatro Argentino, imponente complejo cultural, sede de la Ópera y el Ballet, forma parte del antiguo eje monumental y cuenta con un teatro de prosa, salones de exposición, salas de concierto y una sala lírica con tres niveles de palcos con capacidad para 2200 espectadores. Imagen disponible en Internet en http://www. skyscrapercity.com

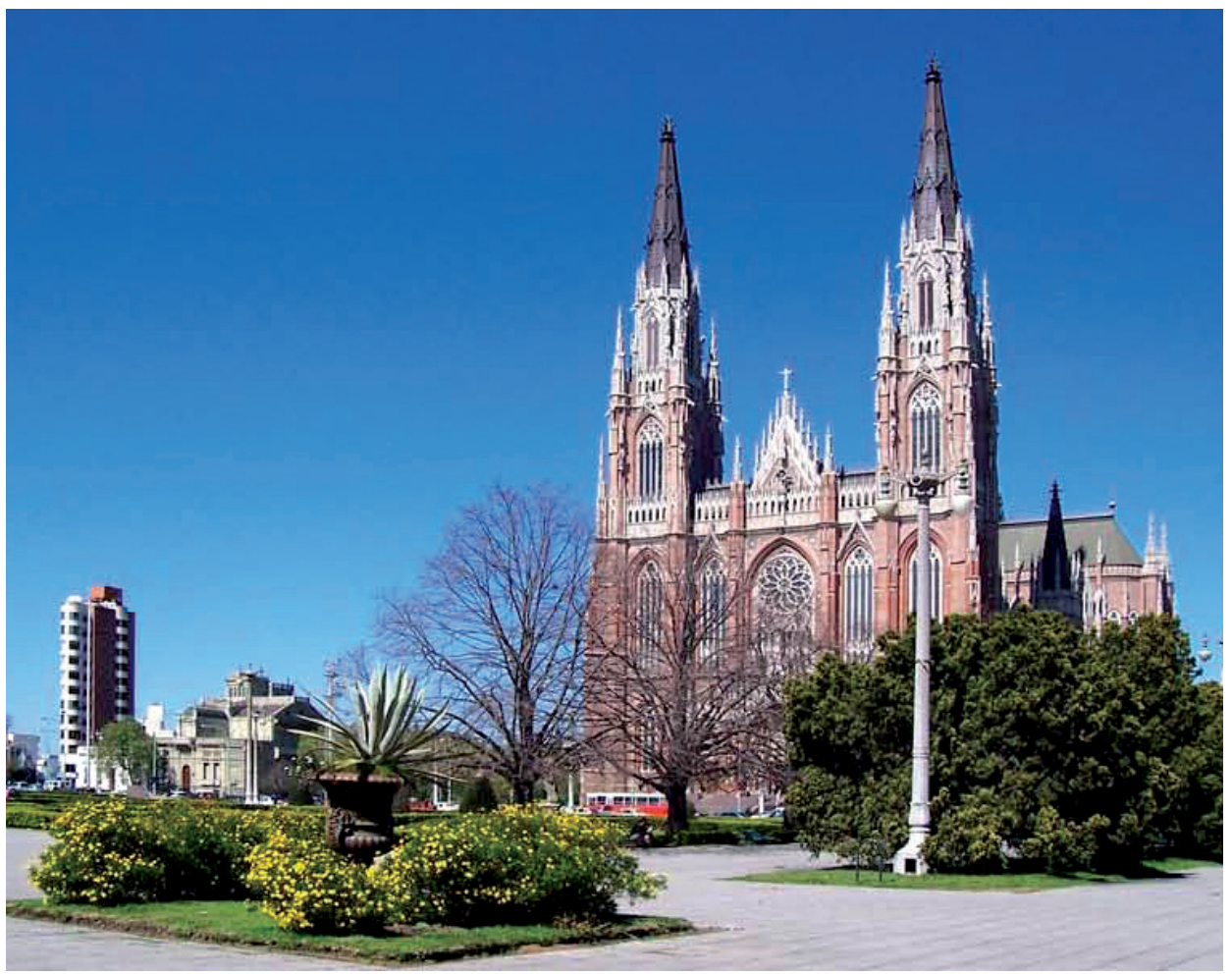

Imagen 12. Catedral de La Inmaculada La Catedral de la Plata o de La Inmaculada Concepción es el mayor Templo Neogótico de América del Sur, se comenzó a edificar en I884 y se inauguró en 1932, en coincidencia con el cincuentenario de la Ciudad, aunque no fue sino hasta 1999 en que se finalizaron las obras con la terminación de sus dos torres. Imagen disponible en Internet en: http://www. skyscrapercity.com 


\section{LOS NUEVOS RETOS URBANOS DE LA PLATA}

La Plata es aún reconocida por su trazado, un cuadrado perfecto con un eje histórico conservado hasta hoy sin ninguna alteración al igual que el diseño sobresaliente de las diagonales que lo cruzan formando rombos dentro de su contorno, bosques y plazas implantadas con exactitud cada seis cuadras. En otras palabras, una ciudad del siglo XXI que respeta el diseño original que se propuso para su fundación, el 19 de noviembre de 1882 (Ver Imagen 13). Sin embargo, la ciudad no es la misma de esa época pues el aumento de la población ha hecho que aparezcan nuevas edificaciones en altura, probablemente en el intento de controlar la expansión urbana a sus áreas de periferia, estrategia que podría privar a sus habitantes de la calidad del espacio público, los edificios públicos y todos los servicios complementarios que se encuentran circunscritos en el famoso cuadrado, dividido por paralelas y diagonales (Ver Imagen I4)

Efectivamente la ciudad crece y asume nuevos retos ya que es el principal centro político, administrativo y educativo de la provincia. Según el censo de 200I (llevado a cabo por

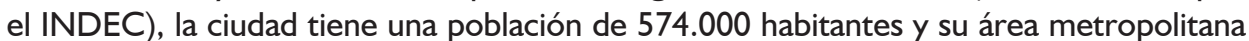
694.000 habitantes $^{21}$. Ante este incremento de la población, los planificadores aún lanzan nuevas propuestas para ordenar el tráfico, como el sistema de estacionamiento, a través de mensajes de texto (SMS), instaurado el 25 de febrero de 2009. Con este hecho, La Plata se convirtió en la primera ciudad de la Argentina en utilizar aplicaciones tecnológicas de primer nivel para controlar el estacionamiento. Posteriormente, en abril de 2009 el Pasaje Rodrigo reabrió sus puertas al público ya que esta galería comercial, inaugurada en 1929 por Basilio Rodrigo (inmigrante español), estuvo cerrada al público por 10 años. Finalmente, el Estadio Ciudad de La Plata será la sede principal de la Copa América de Fútbol, que tras 24 años volverá a disputarse en Argentina, con cabecera en siete provincias del país, entre estas La Plata que albergará varios partidos y la ceremonia inaugural. De esta forma la ciudad apuesta por renovarse en parte a través de los grandes eventos que propicien no sólo una renovación física de la ciudad sino también su imagen ante el resto del mundo ${ }^{22}$.

Imagen 13. Vista aérea de La Plata. La imagen describe por sí sola la propuesta urbana de Pedro Benoit. Imagen disponible en Internet en: http:// www.skyscrapercity.com

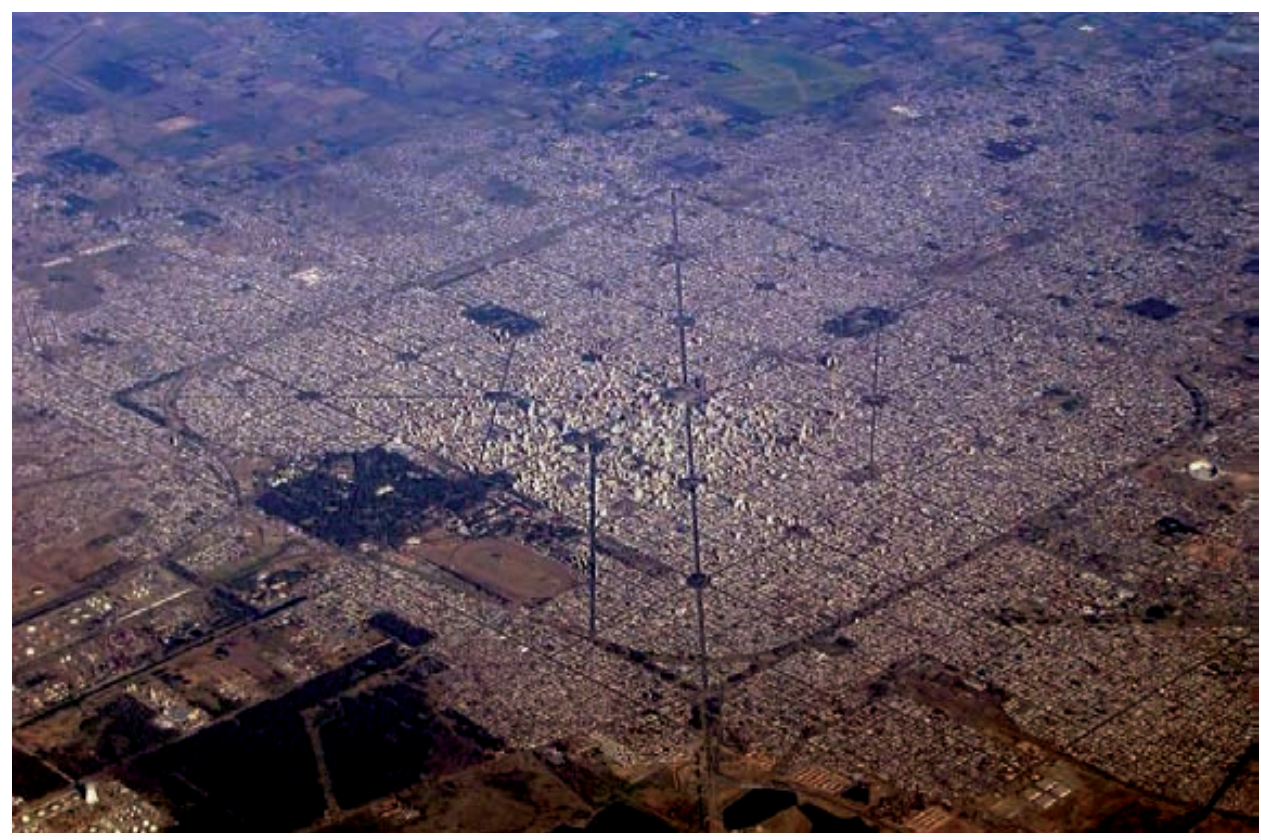

21 La Plata. Información disponible en Internet en: http://www.qwiki.com/

22 Copa América. Argentina 20I I. Información disponible en Internet en: http://www.ca20II.com/ 


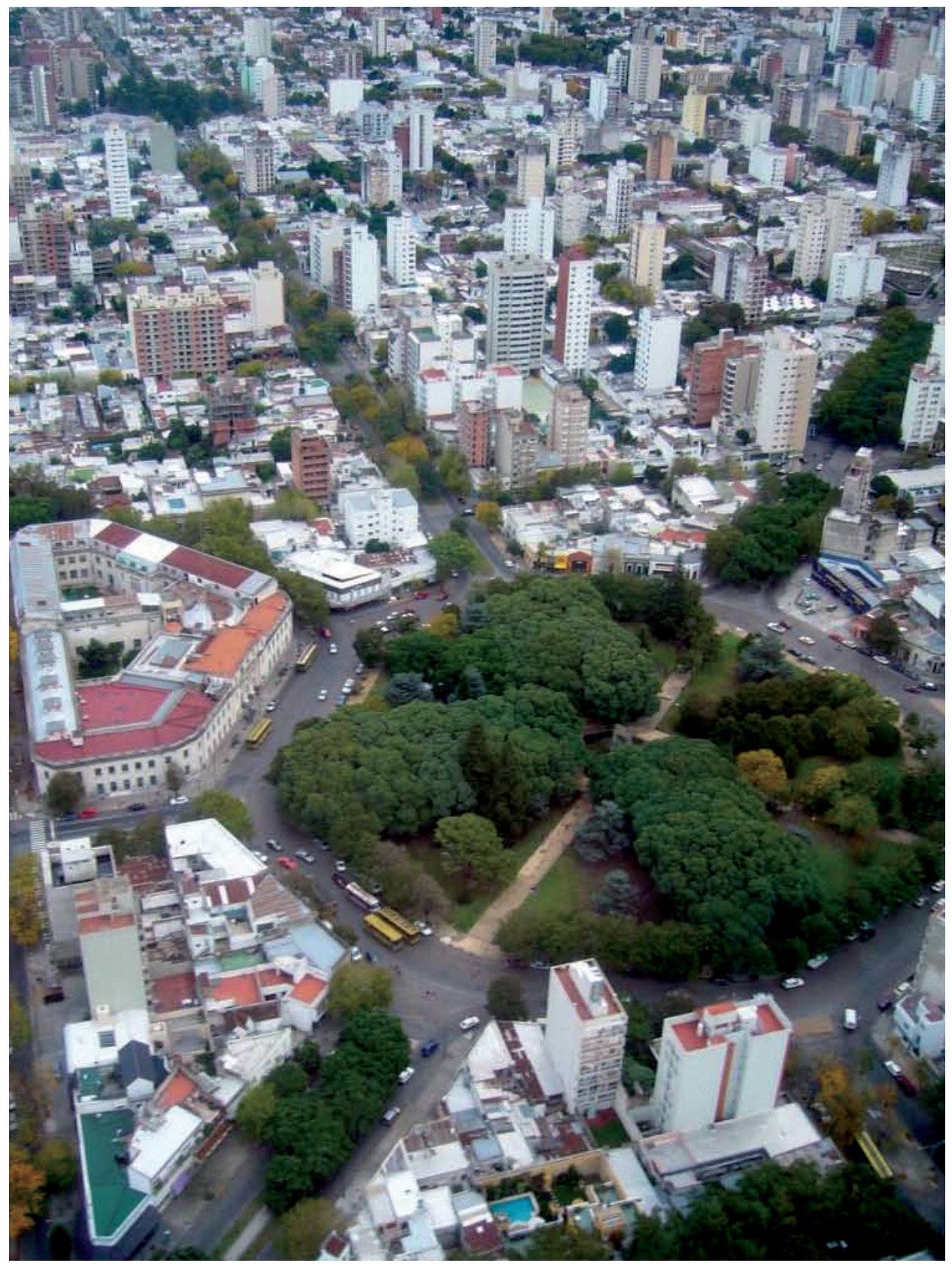

\section{BIBLIOGRAFÍA}

BARBA, Fernando Enrique. Historia de la municipalidad de La Plata. Acción de los gobiernos municipales entre 1882 y 1998. Banco Municipal de la Plata, La Plata, 1999 [I Ed.]

BENÉVOLO, Leonardo. Diseño de la ciudad. Barcelona, Gustavo Gili, 1977
Imagen I4. Fotografía aérea de la ciudad. La ciudad conserva el trazado urbano con el cual se proyectó. Sin embargo el espacio privado refleja claramente el aumento de la densidad poblacional de La Plata, lo que ha hecho que aparezcan nuevas edificaciones en altura, probablemente en el intento de controlar la expansión urbana a sus áreas de periferia y acceder a todos los servicios y equipamientos que se encuentran dentro del cuadrado de Benoit. Fotografia disponible en Internet en: http://www. skyscrapercity. com 
Historia de la Ciudad. Bari, Editorial Laterza, 2006

Los orígenes del urbanismo moderno. Bari, Editorial Laterza, 2005

GRAVAGNUOLO, Benedetto. Historia del urbanismo en Europa, 1750-1960. Madrid, Ediciones Akal, 1998

LEVENE, Ricardo. Historia Argentina y Americana. Ministerio de Cultura de Buenos Aires, Buenos Aires, 2010

MORRIS A.J., Historia de la forma urbana: desde sus orígenes hasta la Revolución industrial, Barcelona, Gustavo Gili, 1984

MUNIZAGA VIGIL, Gustavo. Diseño Urbano: Teoría y Método. Santiago, Editorial Alfaomega, 2002

Las Ciudades y su Historia. Una aproximación. Santiago, Editorial Alfaomega,

2002

PESCI Rubén. Próceres Platenses, Pedro Benoit. Hacedor de un Plan Prodigioso. Disponible en Internet en: http://www.eldia.com.ar/catalogo2/proceres/n9.htm

PICCINATO Luigi., Urbanística medieval, Ed. Dedalo, Bari 1978 


\section{REFERENCIAS WEB}

Ciudad de La Plata. Capital de la Provincia de Buenos Aires. Disponible en Internet en: http://www.interlap.com.ar

Copa América. Argentina 20I I. Disponible en Internet en: http://www. ca20I I.com/

La llustración. Disponible en Internet en http://www.rinconcastellano.com/ilustracion/ ilustracion.html

La Plata. Registro fotográfico. Disponible en Internet en: http://www.skyscrapercity.com

La Plata. Ciudad Mágica. Disponible en Internet en: http://www. laplatamagica.com.ar

La Plata es la capital de la provincia de Buenos Aires. Disponible en Internet en: http:// www.arquba.com/monografias-de-arquitectura/ ciudad-de-la-plata/

La Ciudad de la Plata. Origen de la Ciudad. http://www.laplatainteractiva.com.ar

Municipalidad de la Plata- La Plata. Ciudad para Todos. Disponible en Internet en: www. laciudad.laplata.gov.ar

Semblanza de Dardo Rocha. Constancia No. 7 Disponible en Internet en: http://www. logiaconstancia.org.ar/semblanza_de_dardo_rocha.html

Universidad de La Plata, http://www.unlp.edu.ar/ 